\title{
UM MOMENTO DA DANÇA EM GOIÁS*
}

\section{LENIR MIGUEL DE LIMA}

"É preciso rever, escrever, assinar os autos do passado antes que o tempo passe tudo a
raso."

Cora Coralina

\section{RESUMO}

O presente artigo trata de um breve histórico da dança em Goiás (1973-1983), numa tentativa de registrar seu período de germinação e eclosão nas escolas e academias de Goiânia, a partir da disciplina Rítmica, componente do currículo de Educação Física, na Escola Superior de Educação Física (ESEFEGO).

PALAVRAS-CHAVE: dança - Educação Física - memória - cultura.

E do início da década de 70 que - a partir de um palco vivo, vivido e experienciado falo sobre a dança. Houve um momento em que a dança se encontrava enclausurada em cada um de nós. Houve um momento em que a dança eclodiu e se espalhou de nossos corpos para um coletivo maior. Houve um momento em que a semente germinou, os frutos brotaram, cresceram e se espalharam. Foi neste momento que a dança eclodiu em Goiânia.

Foi neste contexto que, em 1973, retornando à Goiânia - com muitas descobertas e muitas possibilidades - iniciei na Escola Superior de Educação Física (ESEFEGO) um trabalho voltado para a dança. Após dois anos na UFRJ fazendo pós-graduação em dança e vivenciando inúmeros e diferentes estilos com renomados profissionais da área, pude acumular conhecimentos suficientes para dar início à formação de professores de Educação Física, embasando-os para estimular e desenvolver a dança nas escolas.

Iniciava-se, assim, em Goiânia, na ESEFEGO, uma nova disciplina que seria a responsável por todo um movimento artístico-cultural na área de dança. Inicialmente com o nome de Rítmica teve como princípios básicos os fundamentos de Dalcroze (na música), de Isadora Duncan (na dança), através do método criado por Helenita Sá Earp (1917-) - o SISTEMA DE DANÇA UNIVERSAL (SDU).

Para Dalcroze (1865-1950) o corpo é o ponto de passagem obrigatório entre o pensamento e a música; o pensamento só pode captar o ritmo se ele for ditado pelo movimento. Afirmava, ainda, que somente através dos movimentos livres e da utilização do corpo poder-se-ia interpretar e melhor compreender a música. Seu método foi revolucionário e influenciou músicos e bailarinos atrelados aos métodos ortodoxos de execução musical e de coreografias pré-montadas por especialistas, o que impossibilitava a livre expressão (Bourcier, 1987).

Isadora Duncan (1878-1927) foi a pioneira da dança moderna e muito cedo se rebelou contra os cursos de dança acadêmica. Nasceu em São Francisco (Estados Unidos), filha de irlandeses, tornou-se professora de dança aos 14 anos. Para ela a dança é a expressão da vida. A técnica não despertava muito interesse porque o mais importante, para ela, eram os gestos naturais, o reencontro do ritmo inato do homem, o ouvir as pulsações da natureza, a obediência à lei da gravidade, encontrando, assim, uma ligação lógica em que o movimento não pára, mas se trans-forma em outro. Isadora inspirou-se na arte grega, dela retirando 
seus modelos estéticos, e sustentou sua inspiração na música clássica, dela recebendo as emoções que traduziu em movimentos.

Para Isadora a dança é o resultado de um movimento interno, pessoal. Sua vida foi marcada pela luta, ao lado dos povos e dos homens que buscavam a liberdade; em especial reivindicou com obstinação a liberdade da mulher. Seus exemplos foram considerados escandalosos pela burguesia da época (Lever, 1988).

Com estes princípios e a partir do estudo aprofundado do movimento corporal, Helenita Sá Earp criou o Sistema de Dança Universal (SDU) na Escola de Educação Física e Desportos (EEFD) da UFRJ.

Sua preocupação em dar cientificidade a este sistema aproximou-a da anatomia, da fisiologia e da cinesiologia sem, contudo, afastá-la das áreas pedagógica e artística. Neste aspecto desenvolveu, na EEFD/UFRJ, um trabalho junto ao Departamento de Arte Corporal denominado "Dança: princípios e formas fundamentais; bases de sustentação e posições".

A importância do SDU está justamente na valorização de todas as formas do movimento corporal, numa tentativa de buscar, na nomenclatura científica, os conceitos e identificações para as diferentes bases de sustentação e posições do corpo, ultrapassando as limitações do Balé Clássico. Assim, por mais esdrúxulos que possam parecer, quaisquer formas ou movimentos de dança podem ser descritos e decodificados através do SDU.

Devido à pluralidade de combinações de movimentos convencionou-se uma nomenclatura advinda da geometria, partindo-se das formas básicas aos diferentes apoios do corpo em relação aos planos que modificam estas formas. "A forma é a arquitetura do movimento; é o contorno da figura no momento do movimento; o traçado que ela delineia durante o movimento liberado” ( Sá Earp, 1972).

Em sua descrição do movimento quanto à geometria, Sá Earp aborda os planos vertical (sagital, frontal, intermediário) e horizontal (frontal, sagital) em relação ao corpo do dançarino, o que possibilita o seu reconhecimento num determinado tempo-espaço.

A consciência rítmica do movimento, a dinâmica e o equilíbrio interior proporcionam ao dançarino a descoberta da forma perfeita, portanto, do movimento harmônico. Assim, num mesmo desenho (arquitetura do movimento), as diferentes disposições rítmicas associadas aos diferentes graus de tonicidade muscular nas fases de encurtamento e alongamento são determinantes para a diversidade de movimentos, ou seja, do movimento pendular, balanceado, lançado, percutido, vibratório etc. Isto favorece infinitas variações rítmicas, proporcionando características diferentes ao mesmo.

Além disso, o SDU utiliza-se dos elementos da música como a dinâmica e o andamento para ampliar a diversidade do movimento em suas variações quanto à energia utilizada e quanto à velocidade de execução, respectivamente.

Quanto ao acompanhamento, a dança pode se sustentar na palavra (prosa ou verso), na música tradicional, na percussão, em outras formas sonoras de vanguarda ou no próprio silêncio.

Tudo isso possibilita ao dançarino e/ou professor uma universalidade de formas, planos, níveis para criar, compor, coreografar. A coreografia, segundo Sá Earp, deve ser produto do conhecimento quanto à geometria, ao ritmo, à dinâmica e ao andamento, podendo ser abstrata ou figurativa, modificando-se quanto ao estilo (expressão individual, ou de um povo, ou de uma época) e quanto ao caráter ( emoção que caracteriza uma obra de arte). 
Utilizando esta fundamentação teórica e observando a metodologia do SDU iniciamos nosso trabalho na ESEFEGO, primeiramente com os alunos do curso de Educação Física e depois com o Grupo de Dança Univérsica que se formou a partir deles.

Outros movimentos artísticos da época, principalmente no teatro, influenciaram o Grupo de Dança, assim como os trabalhos de Augusto Boal (Teatro do Oprimido) e de Grotowisky (Teatro Pobre) que chegava ao Brasil. Os laboratórios de sensibilização e expressão corporal foram marcantes em nosso trabalho, uma vez que era a partir deles que, coletivamente, criávamos o repertório coreográfico do Grupo.

Pensando a arte como uma manifestação universal do homem, aproximamo-nos de vários artistas goianos ligados às artes plásticas (Sáida Cunha), à música (Estércio Marquez), ao teatro (Hugo Zorzetti e Carlos Fernando Magalhães), à fotografia (Rosary Esteves), à história da arte (Adelmo Café) e à sociologia da arte (Oliveira Leite), procurando entender a dança como uma forma completa de todas estas formas artísticas.

Além disso, o Grupo de Dança Univérsica tinha um compromisso com a ética, com a estética e com o meio social, pois vivíamos os duros anos da ditadura militar.

Nosso trabalho estava comprometido com os temas da cultura brasileira, principalmente com as lendas do folclore nacional.

Tudo isto acontecia muito rapidamente, uma vez que todos nós descobríamos nossas possibilidades corporais e o espaço social que se abria para os espetáculos e palestras que promovíamos.

A dança se expandia e chegava às escolas através de nossos alunos que iniciavam trabalhos em suas aulas de Educação Física, o que nos estimulou a organizar os Festivais Estudantis Goianos de Dança (Lima, 1974).

Assim, de 1974 a 1976, quatro festivais foram realizados com a participação de escolas municipais, estaduais, particulares e academias de dança.

A finalidade principal deste evento, com mostras anuais, era proporcionar um espaço público com todas as condições cênicas (luz/som/cenografia etc.) a estas instituições, objetivando o intercâmbio cultural, pois não havia seleção prévia e nem premiação para os melhores.

O Festival era aberto, portanto, grupos como o do Artesanal dos Cegos e do Instituto Pestalozzi tinham as mesmas oportunidades de se apresentarem publicamente.

Além disso iniciamos um trabalho junto à comunidade goianiense, oferecendo aulas de iniciação à dança para crianças, adolescentes e adultos. Paralelamente nascia o Grupo de Dança da UFG composto por alunos dos diferentes cursos e da comunidade, interessados em aprender e aprofundar na arte de dançar. No período de 1974-1975 mantivemos o Studio Arte Corporal que oferecia cursos regulares de dança, teatro, capoeira e ginástica, também com produções artístico-culturais, participando das Semanas Culturais promovidas pelo Departamento de Cultura da Secretaria de Educação do Estado, na capital e interior de Goiás.

Na UFG, com apoio da Pró-Reitoria de Extensão, o grupo de dança se oficializa com o nome de Grupo Dançarte (1978), em que desenvolvemos um trabalho educativo-artístico em todo o raio de ação da universidade - em Goiânia e nos campi avançados.

Do seio deste trabalho nasceram vários profissionais que saíram para cursos de aperfeiçoamento e especialização no Teatro Guaíra - Paraná, como Tarcísio Clímaco, Dayse Pires, José Reinaldo do Amaral; nos Estados Unidos, Jandernaide Resende e Conceição Viana de Fátima; e no Rio de Janeiro Regina Brito e Zita Ferreira. Os outros que 
aqui permaneceram integraram os grupos de dança emergentes Via Láctea (Faculdade de Arquitetura) e Energia, sob a direção de Julson, como Denise Pires e Marta Carvalho.

De uma série de trabalhos coreográficos destacamos aqueles que marcaram pelo envolvimento com nossas raízes culturais e com o movimento teatral da época: BrasilAfrobrasileiro, com música de percussão criada por Cecelo Coelho especialmente para esta coreografia (1973) ; Ad libtum (1974), com influência dos laboratórios de expressão corporal, numa criação coletiva, com música de Marlos Nobre; Vitória-régia (1976), lenda do Amazonas com músicas de Villa Lobos e Itala Moreira; Senzala (1977), um espetáculo que primou pela expressividade de uma raça sofrida, em que foram pesquisados os movimentos, músicas, danças e rituais dos negros escravos. E, dentro da proposta ideológica do Grupo, esta repressão foi apontada, também, em quadros que representaram a conjuntura política da época, sofrida por nós brasileiros. Raízes da terra (1982) mostrou a origem da raça indígena em Goiás, baseando-se nas lendas dos Karajá, com músicas do Uakiti. A continuidade de vida desta tribo indígena estava seriamente comprometida pela interferência 'civilizadora' do homem branco. Este último trabalho participou da Oficina Nacional de Dança da Bahia, em 1983.

O Grupo Dançarte/UFG participou também de peças teatrais do Grupo de Teatro Universitário, como Antígone dirigida por Carlos Fernando Magalhães e Supysaua, com o Teatro Exercício, dirigida por Hugo Zorzetti.

Em dezembro de 1993, com uma programação cultural incluindo música, poesia e dança, celebramos os "Vinte anos de Dança em Goiás”, numa confraternização que reuniu vários ex-integrantes dos grupos e artistas que sempre nos acompanharam

Completando este revival, recebemos da Secretaria de Cultura de Goiânia o título de Pioneira da Dança em Goiás. 
This article deals about a brief description of dance in Goiás (1973-1983), trying to register a period of germination and eclosion an schools and academies in

Goiânia, from the discipline Rythmics, component of the curriculum of Physical Education, in the Superior Physical Education School (ESEFEGO).

KEY WORDS: Dance - Physical education - Memory - Culture

\section{REFERÊNCIAS BIBLIOGRÁFICAS}

BOURCIER, Paul. História da dança no Ocidente. São Paulo: Martins Fontes, 1987.

LEVER, Maurice. Isadora. São Paulo: Martins Fontes, 1988.

LIMA, Lenir Miguel. Festival Estudantil Goiano de Dança /1974 a 1976. Original datilografado em curso de publicação. (documentos privados).

Os militares, o populismo e suas influências na Educação Física em Goiás. Goiânia, 1992. Dissertação (Mestrado) - Faculdade de Educação, Universidade Federal de Goiás.

SÁ EARP, Maria Helena. As atividades rítmicas educacionais na ENEFD. Rio de Janeiro, 1949. Tese (Livre-docência) - Escola Nacional de Educação Física e Desportos, Universidade Federal do Rio de Janeiro.

.et al. Dança: princípio das formas fundamentais e bases de

sustentação e posições. Rio de Janeiro, 1970. (mimeo).

- Comunicação proferida no III Fórum Goiano sobre Cultura em Goiânia - 30/out a 09/nov/97 -Tema: Memória e Cultura.

- $\quad$ Especialista em dança pela UFRJ, mesa em Educação Escolar pela UFG, coordenadora dos cursos de graduação em Educação Física e especialização em Educação Física Escolar da Faculdade de Educação Física da UFG. 
